\title{
Trapped Fourth Ventricle in Recurrent Acoustic Schwannoma - A Rarity
}

\section{Quarto ventrículo isolado com schwannoma acústico recorrente - uma raridade}

\author{
Vinod Kumar $^{1}$ Ajay Hegde ${ }^{1}$ Rajesh Nair ${ }^{1} \quad$ Girish Menon ${ }^{1}$ \\ ${ }^{1}$ Department of Neurosurgery, Manipal University, Kasturba Medical \\ College Manipal, Manipal, Karnataka, India \\ Arq Bras Neurocir 2017;36:71-74. \\ Address for correspondence Ajay Hegde, MS, (MCh), Manipal \\ University, Kasturba Medical College Manipal, Manipal, Karnataka, \\ India (e-mail: dr.ajayhegde@gmail.com).
}

\begin{abstract}
Keywords

- hydrocephalus

- ventriculoperitoneal shunt

- vestibular schwannoma

- slit ventricle
\end{abstract}

\section{Resumo}

Palavras-chave

- hidrocefalia

- shunt ventriculoperitoneal

- schwannoma vestibular

- fenda ventricular
Fourth ventricular dilatation is usually seen along with tri-ventriculomegaly in patients with communicating hydrocephalus. Isolated fourth ventricular dilatation is uncommon, especially as a sequelae following infective or post hemorrhagic communicating hydrocephalus. Communicating hydrocephalus is reported in vestibular schwannoma with an incidence of 3.7 to $23.5 \%$, but 4 th ventricular dilatation following its treatment has not been reported in the literature. We report a novel case of isolated fourth ventricular obstruction following surgery for recurrent vestibular schwannoma and ventriculoperitoneal shunt placement for communicating hydrocephalus. Management strategies range from endoscopic procedures to ventricular shunt placement. We describe the surgical technique for the placement of a fourth ventricular shunt with the use of a $\mathrm{Y}$ connector.

Em pacientes com hidrocefalia comunicante, a dilatação do quarto ventrículo é normalmente vista acompanhada de triventriculomegalia. A dilatação do quarto ventrículo isolado é incomum, especialmente como uma sequela subsequente à hidrocefalia comunicante infecciosa ou hemorrágica. Hidrocefalia comunicante é relatada em schwannoma vestibular com incidência de 3,7 a 23,5\%, mas a dilatação do quarto ventrículo subsequente ao tratamento não foi encontrada na literatura. Relatamos caso de obstrução do quarto ventrículo isolado subsequente a cirurgia para schwannoma vestibular recorrente e shunt ventriculoperitoneal para hidrocefalia comunicante. As estratégias de manejo variam de procedimentos endoscópicos a shunt ventricular. Descrevemos técnica cirúrgica para alocação de shunt do quarto ventrículo com o uso de conector Y.

\section{Introduction}

Fourth ventricular dilatation is usually seen along with tri-ventriculomegaly in patients with communicating hydrocephalus. Isolated fourth ventricular dilatation is uncom- mon, especially as a sequelae following infective or post hemorrhagic communicating hydrocephalus. ${ }^{1}$ Ventricular shunting often causes a collapse in the system, and postinflammatory scarring in the aqueduct causes adhesions between the ependymal surfaces and secondary ductal received

November 1, 2016 accepted

December 2, 2016

published online

January 30, 2017
Dol http://dx.doi.org/

10.1055/s-0036-1597947. ISSN 0103-5355.
Copyright (c) 2016 by Thieme Revinter

Publicações Ltda, Rio de Janeiro, Brazil
License terms

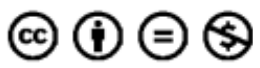


stenosis. ${ }^{2,3}$ This, when coupled with fourth ventricular outlet obstruction, causes isolated dilatation of the fourth ventricle. ${ }^{4}$ We report a novel case of isolated fourth ventricular obstruction following surgery for recurrent vestibular schwannoma.

\section{Case Report}

A 41-year old homemaker, presented with complaints of leftsided headache, left-sided hearing loss and ataxia in June 2011. The preliminary hematological investigations were within normal limits, and neuroimaging along with pure tone audiometry (PTA) and brainstem evoked response audiometry (BERA) diagnosed her with a left cerebellopontine (CP) angle vestibular schwannoma with mild hydrocephalus. She was operated, and underwent a subtotal decompression of the tumor. Her symptoms improved, and she was asymptomatic; however, she was left with a House and Brackmann Grade 4 facial injury.

She presented again in May 2015 with complaints of headache and left-sided ataxia. Repeat imaging revealed a regrowth of the residual vestibular schwannoma with no hydrocephalus (-Fig. 1A). She underwent re-exploration and gross total tumor excision with no further deterioration of her neurologic deficits. Convalescence was unremarkable, and she was discharged after a week.

Her third visit to us was one month after the redo surgery. She presented with complaints of recurrent headache and vomiting, and an increasing tense pseudomeningocele at the operated site. A plain computed tomographic scan of the brain (CT Brain) suggested communicating hydrocephalus

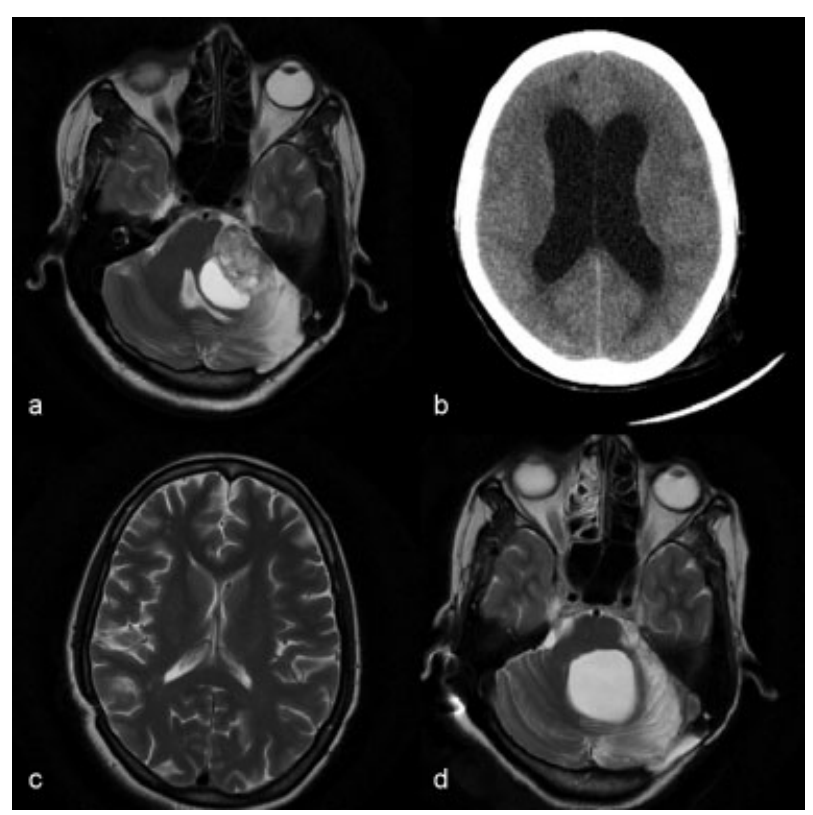

Fig. 1 Preoperative magnetic resonance imaging (MRI) of the brain T2 series, showing heterogeneously hyperintense lesion in the left CP angle cistern suggestive of a schwannoma (a) with hydrocephalus shown on CT (b). Magnetic resonance imaging of the brain T2 series showing chinking of lateral ventricles (c) with Post-op status of the left $\mathrm{CP}$ angle cistern and dilated trapped fourth ventricle (d). with a large pseudomeningocele (-Fig. 1B). A lumbar puncture was performed to rule out post-operative meningitis, and she was shunted using a medium pressure (Chhabra) ventriculo-peritoneal (VP) shunt. She recovered well, and was able to carry out her day-to-day activities for the next 8 months.

In her last admission, she developed vertigo and vomiting with incapacitating gait ataxia over the last 4 months. Serial CT scans showed a collapsed slit-like lateral ventricle with progressive increase in the size of the fourth ventricle ( - Fig. 1C and D). After counselling and careful deliberation, we decided to place a fourth ventricular shunt, since the gait imbalance was hampering her day to day activities.

Procedure: She was placed supine with her head turned to the left in extension. The fourth ventricular entry point was marked along the line joining the inion and mastoid base, at the junction of the medial $1 / 3$ and lateral $2 / 3$. The old Keen's point burr hole was refreshed, and the abdominal end of the shunt system was exposed. A "Y" connector was placed and secured at the cranial end, proximal to shunt chamber. A burr hole was made at the marked point (between the inion and mastoid base), and the ventricular catheter was inserted at an angle perpendicular to the burr hole and advanced till a "loss of resistance" was felt. The ventricular catheter was calculated from a pre-operative magnetic resonance imaging (MRI) of the brain. The shunt tube was secured at the incision and connected to the $Y$ connecter (-Fig. 2). The integrity of the shunt system was confirmed by pumping the chamber and confirming cerebrospinal fluid (CSF) flow at the abdominal end, before it was replaced into the sub-hepatic space.

Post-operative imaging showed a decrease in size of the fourth ventricle with accurate placement of the shunt tip at the fourth ventricular inlet (-Fig. 2). Her symptoms improved postoperatively, and she is on regular follow up.

\section{Discussion}

Trapped fourth ventricles (TFVs) were first described by Dandy in $1921 .^{5}$ They have a reported incidence of $2-3 \%{ }^{6}$ and usually occur when the 4 th ventricle is isolated from the CSF pathway. We believe that with the blockage of the aqueduct and basal cisterns, secondary to adhesions, the entry and exit pathways of the CSF are obstructed, thus causing fourth ventricular dilatation. ${ }^{3,5,7}$ It is most often described in children, secondary to hydrocephalus caused by intraventricular hemorrhage, prematurity or infection. ${ }^{8}$ It is also observed secondary to the functional occlusion of the aqueduct, often related to over-drainage with or without associated slit ventricles. ${ }^{2}$

Hydrocephalus following CP angle vestibular schwannomas has been reported with an incidence of 3.7\% and 23.5\%. ${ }^{9}$ The etiology may be either obstructive or communicative. The obstructive hydrocephalus is due to the blockage of outflow at the fourth ventricle due to the mass effect of the tumor (Hanover $4 \mathrm{~A}, \mathrm{~B}),{ }^{10}$ while the latter is a consequence of the obstruction of CSF absorption at the arachnoid granulation due to high concentrations of protein in the CSF, and 


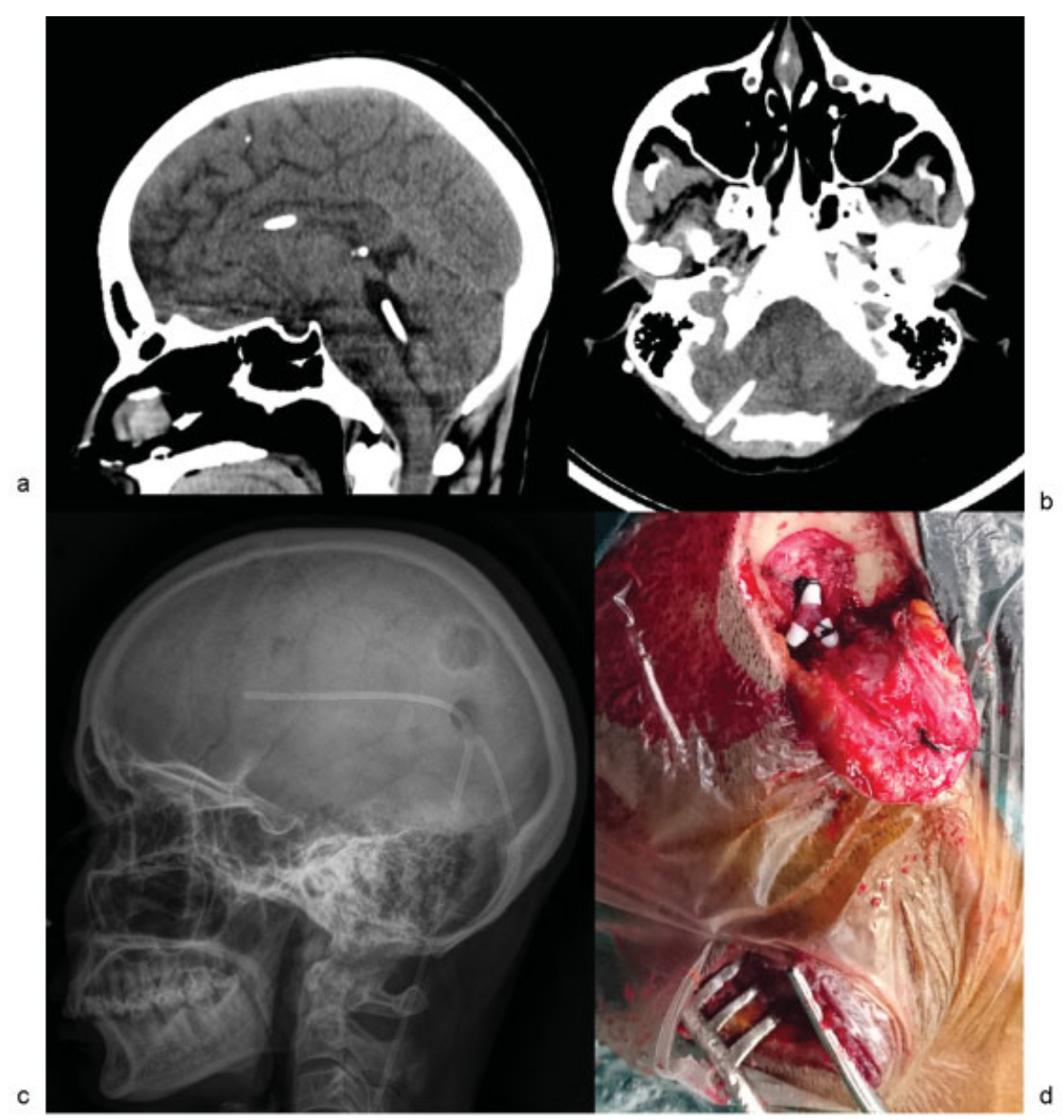

Fig. 2 Postoperative CT scan of the brain showing the ventricular catheter in the lateral and fourth ventricle (a) in sagittal and within fourth ventricle in axial (b). The same can be noted with a skull lateral X-ray (c) and intraoperative color plates showing the "Y" connector between the lateral and fourth ventricular catheters (d).

due to high fibrinogen concentration caused by tumor cells (Antoni B tumors) ${ }^{9}$

The management of hydrocephalus is either with the placement of an external ventricular drain (EVD) (in case of emergencies) or a VP shunt before tumor surgery or tumor removal, which most often resolves the hydrocephalus. However, there are no reports of TFV following VP shunting in CP schwannomas in the literature.

The treatment options for TFV ranges from endoscopic procedures such as aqueductoplasty, aqueductal stenting, and fourth ventricle shunt placement to direct microsurgical approach, veil excision (usually an arachnoid veil) and or outlet fenestration of the fourth ventricle. Uday Kumar et al suggested posterior fossa craniotomy and fourth ventricular fenestration, with or without shunt, as an effective method in the treatment of TFV. Shunt placement has been associated with a high rate of shunt-related complications. ${ }^{11}$ Commonly, both supratentorial peritoneal and fourth ventricle peritoneal shunts are inserted, either separately or connected together, to ensure pressure equilibrium across the tent and prevent reverse or uncal herniation. ${ }^{10}$

Restoration of the physiological CSF pathway has been an unrealistic goal since time immemorial. Conventionally, TFV has been treated with fenestration via microsurgical approach, with or without a supratentorial shunt. ${ }^{11}$ This is done through a suboccipital craniectomy and ultrasoundguided or stereotactic stent insertion. The complications often noted and documented in the literature include cranial nerve palsies, reverse herniation, and other shunt associated complications. Endoscopic procedures have been revived in the recent years due to their advantages. Apart from being minimally invasive, they enhance the visualization of deep cavities and assist in the accurate placement of the ventricular catheter. Endoscopic third ventriculostomy (ETV) alone has a success rate of $76 \%$, and is usually combined with one of the above described procedures to avoid pressure variation across the tentorium and possible herniation. ${ }^{12}$

In our case, the presence of well-drained lateral ventricles prevented us from doing an ETV. Aqueductoplasty is a technically challenging procedure, and in lieu of distorted anatomy, endoscopic procedures have been approached with relative caution. ${ }^{12,13}$ The probability of damaging unidentified structures in the background of anatomical distortion and absence of neuro-navigation prevented us from using endoscopy, and we preferred a more conventional double shunt with a Y-connector as a CSF diversion procedure.

After exploring all surgical options available at our disposal, we planned a fourth ventricle-peritoneal shunt system through a $\mathrm{Y}$ shaped connector attached to the 
preexisting medium pressure Chhabra shunt system. Endoscopic techniques through the lateral ventricle could not be performed in our case in view of the collapsed lateral ventricles. Microsurgical procedures were not considered due to adhesions as a result of two prior surgeries. The $\mathrm{Y}$ shaped connector was used to connect the fourth ventricle with the lateral ventricle to avoid over-drainage of the CSF in any one chamber ${ }^{14}$ and equalize pressures in the supra and infratentorial compartments. Our patient made clinical as well as radiological recovery following the procedure.

\section{References}

1 Scotti G, Musgrave MA, Fitz CR, Harwood-Nash DC. The isolated fourth ventricle in children: CT and clinical review of 16 cases. AJR Am J Roentgenol 1980;135(6):1233-1238

2 Oi S, Matsumoto S. Pathophysiology of aqueductal obstruction in isolated IV ventricle after shunting. Childs Nerv Syst 1986;2(6): 282-286

3 Foltz EL, Shurtleff DB. Conversion of communicating hydrocephalus to stenosis or occlusion of the aqueduct during ventricular shunt. J Neurosurg 1966;24(2):520-529

4 Raimondi AJ, Samuelson G, Yarzagaray L, Norton T. Atresia of the foramina of Luschka and Magendie: the Dandy-Walker cyst. J Neurosurg 1969;31(2):202-216

5 Dandy WE. The diagnosis and treatment of hydrocephalus due to occlusion of the foramina of Magendie and Luschka. Surg Gynecol Obstet $1921 ; 20(13): 112-124$
6 Eder HG, Leber KA, Gruber W. Complications after shunting isolated IV ventricles. Childs Nerv Syst 1997;13(1):13-16

7 Montgomery CT, Winfield JA. Fourth ventricular entrapment caused by rostrocaudal herniation following shunt malfunction. Pediatr Neurosurg 1993;19(4):209-214

8 Fritsch MJ, Kienke S, Manwaring KH, Mehdorn HM. Endoscopic aqueductoplasty and interventriculostomy for the treatment of isolated fourth ventricle in children. Neurosurgery 2004;55(2): 372-377

9 Al Hinai Q, Zeitouni A, Sirhan D, et al. Communicating hydrocephalus and vestibular schwannomas: etiology, treatment, and long-term follow-up. J Neurol Surg B Skull Base 2013; 74(2):68-74

10 Kanayama S, Kohno M, Okamura K, et al. [Case of hydrocephalus associated with vestibular schwannoma, treated by tumor removal]. No Shinkei Geka 2006;34(4):391-395

11 Udayakumaran S, Biyani N, Rosenbaum DP, Ben-Sira L, Constantini S, Beni-Adani L. Posterior fossa craniotomy for trapped fourth ventricle in shunt-treated hydrocephalic children: long-term outcome. J Neurosurg Pediatr 2011;7(1):52-63

12 Longatti P, Basaldella L, Feletti A, Fiorindi A, Billeci D. Endoscopic navigation of the fourth ventricle. Technical note and preliminary experience. Neurosurg Focus 2005;19(6):1-4

13 Longatti P, Fiorindi A, Martinuzzi A, Feletti A. Primary obstruction of the fourth ventricle outlets: neuroendoscopic approach and anatomic description. Neurosurgery 2009;65(6): 1078-1085

14 Spennato P, Cinalli G, Carannante G, Ruggiero C, Del Basso de Caro ML. Multiloculated Hydrocephalus. In: Pediatric Hydrocephalus. Milano: Springer Milan; 2005:219-44 